\title{
Seleksi Penyerang Utama Menggunakan K-Means Clustering Dan Sistem Pendukung Keputusan Metode Topsis
}

\author{
Renenata Ardilesmana Siregar ${ }^{1}$ \\ Sekolah Tinggi Manajemen Informatika Komputer-Raharja ${ }^{l}$ \\ email : renenata.ardilesmana@raharja.info ${ }^{1}$
}

\begin{abstract}
ABSTRAK
Untuk menentukan penyerang ideal dalam sepak bola agar sesuai karakter dan kriteria yang diharapkan, diperlukan pelatih yang mempunyai naluri tajam dan juga sistem yang bisa membantu pelatih dalam memberikan pilihan. Biasanya dalam proses penentuan pemain masih dilakukan secara manual dengan melihat dari karakter dan kriteria dari pemain tersebut. Tetapi terkadang hanya dengan melihat dari karakter dan kriteria dari pemain tersebut saja masih kurang cukup sehingga jauh dari apa yang diharapkan. Untuk mempermudah dalam pemilihan penyerang ideal, maka diperlukan suatu sistem yang dapat membantu pelatih untuk memilih penyerang yang dibutuhkan sesuai dengan kebutuhan tim yaitu dengan menggunakan teknik K-Means Clustering dalam metode data mining sebagai proses dalam menyeleksi pemain untuk bergabung dalam suatu tim dan juga didukung dengan metode Sistem Pendukung Keputusan (Decision Support Systems) The Technique for Order of Preference by Similarity to Ideal Solution (TOPSIS) sebagai proses dalam menentukan penyerang yang akan bermain sebagai pemain utama dalam tim yang menggunakan beberapa kriteria untuk memilih pemain yang tepat. Dengan hasil penelitian ini, diharapkan dapat membantu pelatih dalam proses seleksi pemain dan dapat mengubah cara penilaian terhadap sifat subjektif agar lebih obyektif dalam pengambilan keputusan.
\end{abstract}

\section{Kata Kunci : Data Mining, K-Means Clustering, Sistem Pendukung Keputusan}

\begin{abstract}
To determine the ideal attacker in football to match the expected character and criteria, a coach who has a sharp instinct and a system that can assist the coach in providing choices. Usually in the process of determining the player is still done manually by looking at the characters and criteria of the player. But sometimes just by looking at the characters and criteria of the player is still not enough so far from what is expected. To facilitate the selection of ideal attackers, a system that can help the trainer to select the attacker needed according to the needs of the team is by using K-Means Clustering technique in the method of data mining as a process in selecting players to join a team and also supported by Decision Support Systems method The Technique for Order of Preference by Similarity to Ideal Solution (TOPSIS) is the process of determining which attacker will play as a major player in the team using multiple criteria to select the right player. With the results of this study, it is expected to assist trainers in the selection process of players and can change the way the assessment of the subjective nature to be more objective in decision making.
\end{abstract}

Keywords: Data Mining, K-Means Clustering, Decision Support System 


\section{PENDAHULUAN}

Sepakbola adalah tim yang terdiri dari sebelas orang pemain. Ada yang bertugas sebagai kiper, pemain belakang, pemain tengah, dan juga pemain depan. Pemain depan merupakan pemain yang mempunyai tugas untuk memasukkan bola ke dalam gawang lawan agar bisa memberikan kemenangan timnya. Dalam memilih seorang penyerang, seorang pelatih masih melakukan seleksi secara manual dengan penilaian karakter dan kriteria pemain saja. Perkembangan teknologi yang ada di dunia sepak bola dalam proses menyeleksi dan pemilihan pemain agar sesuai dengan karakter dan kriteria yang diharapkan pelatih dirasakan masih belum berkembang. Hal ini dilihat dari belum adanya sistem komputerisasi yang mampu menyediakan pilihan bagi para pelatih sebagai sarana pendukung dalam mengambil suatu keputusan.

Seorang pelatih masih merasa kesulitan dalam memilih pemain yang tepat dalam proses penyeleksian pemain, sehingga masih ada pelatih yang belum bisa menilai pemain secara objektif. Dimana, para pemain memang benar-benar dinilai dari kemampuan mereka sendiri bukan dari penilaian secara subjektif saja. Selain itu juga, pada umumnya proses pengambilan keputusan di dalam menentukan pemain masih mengandalkan insting pelatih. Agar pemilihan pemain bisa sesuai dengan kriteria yang diharapkan, perlu dilakukan proses penyeleksian pemain terlebih dahulu. Dimana, pelatih akan melakukan pengamatan secara langsung dengan melihat teknik bermain setiap pemain, baik secara individu maupun kerjasama secara tim. Lalu, akan dilakukan penilaian dari pengamatan tersebut. Namun dikarenakan penilaian pemain yang masih manual, maka pelatih membutuhkan waktu lebih dan kecermatan dalam proses untuk menentukan posisi yang tepat untuk pemain itu sendiri.

\section{PERMASALAHAN}

Dari paparan tersebut diatas menunjukkan bahwa seorang pelatih membutuhkan sistem untuk memudahkan pemilihan pemain dengan tepat. Untuk itu, penulis mencoba melakukan penelitian terhadap salah satu tim nasional sepakbola dunia yaitu Prancis untuk memudahkan penelitian dengan memilih beberapa pemain yang bergabung dalam tim nasional Prancis kemudian diambil data-datanya berupa berapa kali pemain tersebut membela klubnya selama satu musim dan berapa banyak gol yang telah diciptakan untuk klubnya. Data-data yang telah didapatkan tadi kemudian diolah untuk mengetahui pola dari data-data tersebut sehingga dapat diambil informasi-informasi apa saja yang tersembunyi dari data-data tersebut. Metode pengolahan data seperti ini sering disebut sebagai data mining. Pada penelitian ini, analisa data mining dilakukan dengan menggunakan metode $K$-Means Clustering. Dengan menggunakan metode ini, data-data yang telah didapatkan dikelompokan ke dalam beberapa cluster berdasarkan kemiripan dari data-data tersebut, sehingga data-data yang memiliki karakteristik yang sama dikelompokan dalam satu cluster dan yang memliki karakteristik yang berbeda dikelompokan dalam cluster yang lain yang memiliki karakteristik yang sama.

Setelah data tersebut dikelompokkan, kemudian penulis mencoba untuk membuat suatu sistem pendukung keputusan untuk menentukan siapa yang akan menjadi penyerang utama untuk bermain dari menit pertama. Sistem pendukung keputusan yang digunakan adalah metode Topsis. Metode ini dipilih karena mampu menyeleksi keputusan terbaik dari sejumlah keputusan yang dihasilkan berdasarkan kriteria yang 
telah ditetapkan. Dengan menggunakan metode K-Means Clustering dan Topsis diharapkan dapat membantu pelatih dalam proses seleksi pemain.

\section{METODOLOGI PENELITIAN}

Pada penelitian ini, dimulai dari melakukan pencarian data penyerang tim nasional Prancis sebagai dasar untuk melakukan penelitian. Dalam penelitian ini, seorang pelatih disimulasikan mengingingkan 5 orang penyerang untuk dibawa ke dalam tim nasional Prancis. Data-data yang digunakan pada penelitian ini didapat dari salah satu situs website di internet yang berupa data pemain yang pernah masuk dalam tim nasional Prancis selama tahun 2016. Dalam penelitian ini hanya beberapa atribut data saja yang digunakan, seperti berapa kali pemain tersebut membela klubnya selama satu musim dan berapa banyak gol yang telah diciptakan untuk klubnya. Data-data yang telah didapatkan tersebut merupakan data-data yang berjenis data nominal. Data-data yang berjenis nominal tersebut diinisialisasikan ke dalam bentuk angka melalui beberapa langkah agar data-data yang berjenis data nominal dapat diolah dengan menggunakan K-means Clustering. Semua data yang telah didapatkan tadi kemudian diolah untuk dapat dianalisa sehingga menghasilkan informasi yang berguna untuk mengatasi permasalahan tersebut. Pengolahan data ini menggunakan salah satu teori dari data mining yaitu K-Means Clustering. Dengan metode ini, data yang diperoleh dikelompokkan berdasar kemiripan karakteristik dari setiap data, sehingga dapat ditemukan informasi yang tersembunyi dari data-data tersebut.

Setelah melakukan metode data mining, langkah selanjutnya adalah membuat Sistem Pengambilan Keputusan guna menentukan siapa yang akan menjadi penyerang utama untuk bermain dari menit pertama. Sistem pendukung keputusan yang digunakan adalah metode Topsis. Metode ini dipilih karena mampu menyeleksi keputusan terbaik dari sejumlah keputusan yang dihasilkan berdasarkan kriteria yang telah ditetapkan. Semua data yang telah didapatkan tadi diharapkan dapat menghasilkan informasi yang berguna untuk mengatasi permasalahan tersebut.

\section{HASIL DAN PEMBAHASAN}

\subsection{Data}

Data yang diperlukan dalam penelitian ini diperoleh melalui salah satu situs website di internet yang berupa data Prancis yang telah dipanggil selama tahun 2016. Datadata tersebut berisi data diri pemain Prancis, namun dalam penelitian ini hanya beberapa atribut data saja yang digunakan, seperti nama pemain, jumlah penampilan dalam klub dan jumlah gol yang dicetak. Berikut ini adalah data pemain pada tahun 2016 .

Tabel 1 Data Pemain Prancis Tahun 2016

\begin{tabular}{|c|c|c|c|}
\hline \multirow{2}{*}{ NO } & Nama Pemain & $\begin{array}{c}\text { Penampilan Klub } \\
(\mathrm{X})\end{array}$ & $\begin{array}{c}\text { Gol } \\
(\mathrm{Y})\end{array}$ \\
\hline 1 & Antoine Griezmann & 53 & 26 \\
\hline 2 & Nabil Fekir & 49 & 14 \\
\hline 3 & Ousmane Dembélé & 49 & 10 \\
\hline
\end{tabular}




\begin{tabular}{|c|c|c|c|}
4 & André Pierre Gignac & 48 & 26 \\
\hline 5 & Karim Benzema & 48 & 19 \\
\hline 6 & Alexandre Lacazette & 45 & 37 \\
\hline 7 & Kylian Mbappé & 44 & 26 \\
\hline 8 & Florian Thauvin & 43 & 15 \\
\hline 9 & Kevin Gameiro & 42 & 16 \\
\hline 10 & Anthony Martial & 42 & 8 \\
\hline 11 & Oliver Girourd & 39 & 16 \\
\hline 12 & Dimitri Payet & 39 & 8 \\
\hline 13 & Kingsley Coman & 25 & 2 \\
\hline
\end{tabular}

\subsection{Pengolahan data}

Untuk dapat melakukan pengelompokan data-data tersebut menjadi beberapa cluster perlu dilakukan beberapa langkah, yaitu:

1. Tentukan jumlah cluster yang diinginkan. Ada beberapa cara untuk menentukan jumlah klaster. Dalam hal ini peneliti menggunakan rumus estimasi $\frac{\sqrt{n}}{2}$ dimana $\mathrm{n}$ adalah jumlah objek data.

$\frac{\sqrt{13}}{2}=2,54$. Jadi jumlah cluster yang bisa dihasilkan adalah 2-3 cluster.

2. Tentukan titik pusat awal dari setiap cluster. Dalam penelitian ini titik pusat awal ditentukan secara random dan didapat titik pusat dari setiap cluster pada tabel 2.

Tabel 2 Titik Pusat Awal Setiap Cluster

\begin{tabular}{|c|c|c|c|}
\hline NO & Nama Pemain & $\begin{array}{c}\text { Penampilan } \\
(\mathrm{X})\end{array}$ & $\begin{array}{c}\text { Gol } \\
\text { (Y) }\end{array}$ \\
\hline C1 & $\begin{array}{c}\text { André Pierre } \\
\text { Gignac }\end{array}$ & 48 & 26 \\
\hline C2 & Oliver Girourd & 39 & 16 \\
\hline
\end{tabular}

3. Tempatkan setiap data pada cluster. Dalam penelitian ini digunakan metode $\mathrm{k}$ means untuk mengalokasikan setiap data ke dalam suatu cluster, sehingga data akan dimasukan dalam suatu cluster yang memiliki jarak paling dekat dengan titik pusat dari setiap cluster. Untuk mengetahui cluster mana yang paling dekat dengan data, maka perlu dihitung jarak setiap data dengan titik pusat setiap cluster. Ada beberapa formula yang digunakan untuk menghitung jarak setiap data. Dalam hal ini peneliti menggunakan rumus Euclidean Distance $\mathrm{D}\left(\mathrm{X}_{2}, \mathrm{X}_{1}\right)=$ $\sqrt{\sum_{j=1}^{d}\left|x_{2} \mathrm{j}-x_{1} \mathrm{j}\right|^{2}}$

$$
=\sqrt{\left(x_{i 1}-x_{j 1}\right)^{2}+\left(x_{i 2}-x_{j 2}\right)^{2}+\cdots+\left(x_{i p}-x_{j p}\right)^{2}}
$$


Hasilnya dapat dilihat pada tabel 3 dibawah ini.

Tabel 3 Jarak Setiap Data Dengan Titik Pusat Awal Setiap Cluster

\begin{tabular}{|c|c|c|c|c|c|c|}
\hline NO & Nama Pemain & Penampilan & Gol & C1 & C2 & $\begin{array}{c}\text { Jarak } \\
\text { Terpendek }\end{array}$ \\
\hline 1 & $\begin{array}{c}\text { Antoine } \\
\text { Griezmann }\end{array}$ & 53 & 26 & $\mathbf{5}$ & 17,20465053 & $\mathbf{5}$ \\
\hline 2 & Nabil Fekir & 49 & 14 & 12,04159 & $\mathbf{1 0 , 1 9 8 0 3 9 0 3}$ & $\mathbf{1 0 , 1 9 8 0 3 9 0 3}$ \\
\hline 3 & $\begin{array}{c}\text { Ousmane } \\
\text { Dembélé }\end{array}$ & 49 & 10 & 16,03122 & $\mathbf{1 1 , 6 6 1 9 0 3 7 9}$ & $\mathbf{1 1 , 6 6 1 9 0 3 7 9}$ \\
\hline 4 & $\begin{array}{c}\text { André Pierre } \\
\text { Gignac }\end{array}$ & 48 & 26 & $\mathbf{0}$ & 13,45362405 & $\mathbf{0}$ \\
\hline 5 & $\begin{array}{c}\text { Karim } \\
\text { Benzema }\end{array}$ & 48 & 19 & $\mathbf{7}$ & 9,486832981 & $\mathbf{7}$ \\
\hline 6 & $\begin{array}{c}\text { Alexandre } \\
\text { Lacazette }\end{array}$ & 45 & 37 & $\mathbf{1 1 , 4 0 1 7 5}$ & 21,84032967 & $\mathbf{1 1 , 4 0 1 7 5 4 2 5}$ \\
\hline 7 & Kylian Mbappé & 44 & 26 & $\mathbf{4}$ & 11,18033989 & $\mathbf{4}$ \\
\hline 8 & $\begin{array}{c}\text { Florian } \\
\text { Thauvin }\end{array}$ & 43 & 15 & 12,08305 & $\mathbf{4 , 1 2 3 1 0 5 6 2 6}$ & $\mathbf{4 , 1 2 3 1 0 5 6 2 6}$ \\
\hline 9 & Kevin Gameiro & 42 & 16 & 11,6619 & $\mathbf{3}$ & $\mathbf{3}$ \\
\hline 10 & $\begin{array}{c}\text { Anthony } \\
\text { Martial }\end{array}$ & 42 & 8 & 18,97367 & $\mathbf{8 , 5 4 4 0 0 3 7 4 5}$ & $\mathbf{8 , 5 4 4 0 0 3 7 4 5}$ \\
\hline 11 & Oliver Girourd & 39 & 16 & 13,45362 & $\mathbf{0}$ & $\mathbf{0}$ \\
\hline 12 & Dimitri Payet & 39 & 8 & 20,12461 & $\mathbf{8}$ & $\mathbf{8}$ \\
\hline 13 & $\begin{array}{c}\text { Kingsley } \\
\text { Coman }\end{array}$ & 25 & 2 & 33,24154 & $\mathbf{1 9 , 7 9 8 9 8 9 8 7}$ & $\mathbf{1 9 , 7 9 8 9 8 9 8 7}$ \\
\hline
\end{tabular}

4. Setelah semua data ditempat ke dalam cluster yang terdekat, kemudian hitung kembali pusat cluster yang baru berdasarkan rata-rata anggota yang ada pada cluster tersebut. Hasilnya pada tabel 4 dibawah ini.

$\mathrm{C} 1_{(\mathrm{x})}=\frac{53+48+48+45+44}{5}=47.6$

$\mathrm{C} 1_{(\mathrm{y})}=\frac{26+26+19+37+26}{5}=26,8$

$\mathrm{C} 2(\mathrm{x})=\frac{49+49+43+42+42+39+39+25}{8}=41$

$\mathrm{C} 2_{(\mathrm{y})}=\frac{14+10+15+16+8+16+8+2}{8}=11,125$

Tabel 4. Pusat cluster baru berdasarkan rata-rata anggota yang ada

\begin{tabular}{|c|c|c|c|c|c|}
\hline \multirow{2}{*}{ NO } & \multirow{2}{*}{ Nama Pemain } & Penampilan & \multirow{2}{*}{$\begin{array}{c}\text { Gol } \\
(\mathrm{X})\end{array}$} & \multicolumn{2}{|c|}{ Cluster Baru } \\
\cline { 5 - 6 } & & $(\mathrm{Y})$ & $\mathrm{C} 1$ & $\mathrm{C} 2$ \\
\hline
\end{tabular}




\begin{tabular}{|c|c|c|c|c|c|}
\hline 1 & $\begin{array}{c}\text { Antoine } \\
\text { Griezmann }\end{array}$ & 53 & 26 & 47,6 & 41 \\
\hline 2 & Nabil Fekir & 49 & 14 & 26,8 & 11,125 \\
\hline 3 & Ousmane Dembélé & 49 & 10 & & \\
\hline 4 & $\begin{array}{c}\text { André Pierre } \\
\text { Gignac }\end{array}$ & 48 & 26 & & \\
\hline 5 & Karim Benzema & 48 & 19 & & \\
\hline 6 & $\begin{array}{c}\text { Alexandre } \\
\text { Lacazette }\end{array}$ & 45 & 37 & & \\
\hline 7 & Kylian Mbappé & 44 & 26 & & \\
\hline 8 & Florian Thauvin & 43 & 15 & & \\
\hline 9 & Kevin Gameiro & 42 & 16 & & \\
\hline 10 & Anthony Martial & 42 & 8 & & \\
\hline 11 & Oliver Girourd & 39 & 16 & & \\
\hline 12 & Dimitri Payet & 39 & 8 & & \\
\hline 13 & Kingsley Coman & 25 & 2 & & \\
\hline
\end{tabular}

5. Setelah didapatkan titik pusat yang baru dari setiap cluster, lakukan kembali dari langkah ketiga hingga titik pusat dari setiap cluster tidak berubah lagi dan tidak ada lagi data yang berpindah dari satu cluster ke cluster yang lain. Dengan menggunakan rumus pada no 3 hasilnya dapat dilihat pada tabel 5 dibawah ini.

Tabel 5 Pusat cluster baru berdasarkan rata-rata anggota yang ada

\begin{tabular}{|c|c|c|c|c|c|c|}
\hline NO & Nama Pemain & Penampilan & Gol & C1 & C2 & $\begin{array}{c}\text { Jarak } \\
\text { Terpendek }\end{array}$ \\
\hline 1 & Antoine Griezmann & 53 & 26 & $\mathbf{5 , 4 5 8 9 3 8}$ & 19,11192 & 5,458937626 \\
\hline 2 & Nabil Fekir & 49 & 14 & 12,87633 & $\mathbf{8 , 5 0 0 9 1 9}$ & 8,500919068 \\
\hline 3 & Ousmane Dembélé & 49 & 10 & 16,85823 & $\mathbf{8 , 0 7 8 7 1 4}$ & 8,078714316 \\
\hline 4 & $\begin{array}{c}\text { André Pierre } \\
\text { Gignac }\end{array}$ & 48 & 26 & $\mathbf{0 , 8 9 4 4 2 7}$ & 16,43976 & 0,894427191 \\
\hline 5 & Karim Benzema & 48 & 19 & $\mathbf{7 , 8 1 0 2 5}$ & 10,5364 & 7,810249676 \\
\hline 6 & Alexandre & 45 & 37 & $\mathbf{1 0 , 5 2 6 1 6}$ & 26,18235 & 10,52615789 \\
\hline 7 & Lacazette & 44 & 26 & $\mathbf{3 , 6 8 7 8 1 8}$ & 15,17451 & 3,687817783 \\
\hline 8 & Kylian Mbappé & 43 & 15 & 12,66491 & $\mathbf{4 , 3 6 0 6 9 1}$ & 4,360690886 \\
\hline 9 & Kevin Gameiro & 42 & 16 & 12,16553 & $\mathbf{4 , 9 7 6 5 0 7}$ & 4,976507309 \\
\hline 10 & Anthony Martial & 42 & 8 & 19,61632 & $\mathbf{3 , 2 8 1 1 0 1}$ & 3,281101187 \\
\hline 11 & Oliver Girourd & 39 & 16 & 13,8058 & $\mathbf{5 , 2 6 9 3 1}$ & 5,269309727 \\
\hline 12 & Dimitri Payet & 39 & 8 & 20,67365 & $\mathbf{3 , 7 1 0 2 0 6}$ & 3,71020552 \\
\hline 13 & Kingsley Coman & 25 & 2 & 33,55294 & $\mathbf{1 8 , 4 1 9 1 6}$ & 18,41916461 \\
\hline
\end{tabular}


Dalam penelitian ini, iterasi clustering data mahasiswa terjadi sebanyak 2 kali iterasi. Pada iterasi ke-2 ini, titik pusat dari setiap cluster sudah tidak berubah dan tidak ada lagi data yang berpindah dari satu cluster ke cluster yang lain.

Tabel 6 Pengelompokkan Data

\begin{tabular}{|c|c|c|}
\hline No. & C1 & C2 \\
\hline 1 & 1 & \\
\hline 2 & & 1 \\
\hline 3 & & 1 \\
\hline 4 & 1 & \\
\hline 5 & 1 & \\
\hline 6 & 1 & \\
\hline 7 & 1 & \\
\hline 8 & & 1 \\
\hline 9 & & 1 \\
\hline 10 & & 1 \\
\hline 11 & & 1 \\
\hline 12 & & 1 \\
\hline 13 & & 1 \\
\hline
\end{tabular}

Berdasarkan hasil pengelompokan data menggunakan metode k-means clustering, di dapatkan hasil clustering hingga iterasi ke-2, dimana titik pusat tidak lagi berubah dan tidak ada data yang berpindah antar cluster. Hasil dari clustering tersebut seperti pada tabel 7 .

Tabel 7 Hasil Pengelompokkan Data Berdasarkan Kebutuhan Pelatih

\begin{tabular}{|c|c|}
\hline CLUSTER 1 & CLUSTER 2 \\
\hline $\begin{array}{l}\text { Terdiri dari } 5 \text { orang yaitu Antoine } \\
\text { Griezmann, André Pierre } \text { Gignac, } \\
\text { Karim Benzema, Alexandre Lacazette, } \\
\text { Kylian Mbappé dengan rata-rata } \\
\text { penampilan 47,6 dan rata-rata gol } 26,8\end{array}$ & $\begin{array}{l}\text { Terdiri dari } 8 \text { orang yaitu Nabil Fekir, } \\
\text { Ousmane Dembélé, Florian Thauvin, Kevin } \\
\text { Gameiro, Oliver Girourd, Anthony Martial, } \\
\text { Dimitri Payet, Kingsley Coman dengan rata- } \\
\text { rata penampilan } 41 \text { dan rata-rata gol } 11,125\end{array}$ \\
\hline
\end{tabular}

6. Menentukan matriks ternomalisasi

Setelah dilakukan pengelompokkan data berdasarkan kebutuhan pelatih, maka langkah selanjutnya adalah membuat sistem pengambil keputusan siapa yang akan menjadi penyerang utama dalam tim. Hal pertama yang dilakukan adalah mencari matriks keputusan ternomalisasi. Dalam menentukan matriks keputusan ternormalisasi, nilai tiap kriteria (xij) untuk keseluruhan alternatif dijumlahkan kemudian nilai masing-masing kriteria tersebut dibagi dengan hasil jumlah kriterianya. 
Tabel 8 Hasil Pengelompokkan Data Cluster 1

\begin{tabular}{|c|c|c|c|}
\hline NO & Nama Pemain & Penampilan & Gol \\
\hline 1 & Antoine Griezmann & 53 & 26 \\
\hline 2 & $\begin{array}{c}\text { André Pierre } \\
\text { Gignac }\end{array}$ & 48 & 26 \\
\hline 3 & Karim Benzema & 48 & 19 \\
\hline 4 & $\begin{array}{c}\text { Alexandre } \\
\text { Lacazette }\end{array}$ & 45 & 37 \\
\hline 5 & Kylian Mbappé & 44 & 26 \\
\hline
\end{tabular}

a) Untuk kriteria penampilan (C1) :

$$
\begin{aligned}
& |C 1|=\sqrt{(53)^{2}+(48)^{2}+(48)^{2}+(45)^{2}+(44)^{2}}=106,6677083 \\
& \mathrm{R}_{11}=\mathrm{X}_{11} / \mathrm{C}_{1}=53 / 106,6677083=0,496870148 \\
& \mathrm{R}_{21}=\mathrm{X}_{21} / \mathrm{C}_{1}=48 / 106,6677083=0,449995606 \\
& \mathrm{R}_{31}=\mathrm{X}_{31} / \mathrm{C}_{1}=48 / 106,6677083=0,449995606 \\
& \mathrm{R}_{41}=\mathrm{X}_{41} / \mathrm{C}_{1}=45 / 106,6677083=0,421870880 \\
& \mathrm{R}_{51}=\mathrm{X}_{51} / \mathrm{C}_{1}=44 / 106,6677083=0,412495972
\end{aligned}
$$

b) Untuk kriteria gol (C2) :

$$
\begin{aligned}
& |C 2|=\sqrt{(26)^{2}+(26)^{2}+(19)^{2}+(37)^{2}+(26)^{2}}=61,3025285 \\
& \mathrm{R}_{11}=\mathrm{X}_{11} / \mathrm{C}_{1}=26 / 61,3025285=0,424126062 \\
& \mathrm{R}_{21}=\mathrm{X}_{21} / \mathrm{C}_{1}=26 / 61,3025285=0,424126062 \\
& \mathrm{R}_{31}=\mathrm{X}_{31} / \mathrm{C}_{1}=19 / 61,3025285=0,309938276 \\
& \mathrm{R}_{41}=\mathrm{X}_{41} / \mathrm{C}_{1}=37 / 61,3025285=0,603564011 \\
& \mathrm{R}_{51}=\mathrm{X}_{51} / \mathrm{C}_{1}=26 / 61,3025285=0,424126062
\end{aligned}
$$

Tabel 9 Matriks Ternormanilasi

\begin{tabular}{|l|l|}
\hline 0,496870148 & 0,424126062 \\
0,449995606 & 0,424126062 \\
0,449995606 & 0,309938276 \\
0,421870880 & 0,603564011 \\
0,412495972 & 0,424126062 \\
\hline
\end{tabular}

7. Menentukan matriks keputusan normalisasi terbobot

Tabel 10 Kriteria

\begin{tabular}{|c|l|}
\hline Nilai & \multicolumn{1}{|c|}{ Kriteria } \\
\hline 1 & Sangat tidak \\
2 & penting \\
3 & Tidak penting \\
4 & Cukup penting \\
\hline
\end{tabular}


Sebelum menghitung \begin{tabular}{|c|l|l|} 
\\
5 & Sangat penting & \\
matrik keputusan normalisasi terbobot, tentukan terlebih
\end{tabular} dahulu bobot dari tiap-tiap kriteria. Tingkat kepentingan tiap kriteria tertera pada tabel 10.

Nilai bobot awal (w) digunakan untuk menunjukkan tingkat kepentingan relatif dari setiap kriteria. Bobot dari masing-masing kriteria tertera pada Tabel 11.

Tabel 11 Bobot Kriteria

\begin{tabular}{|c|c|c|}
\hline Nilai & Kriteria & Kriteria \\
\hline 1 & Penampilan & 3 \\
2 & Gol & 5 \\
\hline
\end{tabular}

Setelah menentukan bobot dari masing-masing kriteria, maka berdasarkan persamaan 1, dapat menghitung matrik normalisasi terbobot yaitu:

a) Untuk kriteria penampilan :

$$
\begin{aligned}
& \mathrm{Y}_{11}=\mathrm{W}_{11} / \mathrm{R}^{11}=3 / 0,496870148=6,037794811 \\
& \mathrm{Y}_{21}=\mathrm{W}_{11} / \mathrm{R}^{21}=3 / 0,449995606=6,666731771 \\
& \mathrm{Y}_{31}=\mathrm{W}_{11} / \mathrm{R}^{31}=3 / 0,449995606=6,666731771 \\
& \mathrm{Y}_{41}=\mathrm{W}_{11} / \mathrm{R}^{41}=3 / 0,421870880=7,111180555 \\
& \mathrm{Y}_{51}=\mathrm{W}_{11} / \mathrm{R}^{51}=3 / 0,412495972=7,272798295
\end{aligned}
$$

b) Untuk kriteria gol :

$$
\begin{aligned}
& \mathrm{Y}_{11}=\mathrm{W}_{11} / \mathrm{R}^{11}=5 / 0,424126062=11,78894779 \\
& \mathrm{Y}_{21}=\mathrm{W}_{11} / \mathrm{R}^{21}=5 / 0424126062=11,78894779 \\
& \mathrm{Y}_{31}=\mathrm{W}_{11} / \mathrm{R}^{31}=5 / 0,309938276=16,13224434 \\
& \mathrm{Y}_{41}=\mathrm{W}_{11} / \mathrm{R}^{41}=5 / 0,603564011=8,284125472 \\
& \mathrm{Y}_{51}=\mathrm{W}_{11} / \mathrm{R}^{51}=5 / 0,424126062=11,78894779
\end{aligned}
$$

Tabel 12 Matrik Ternormanilasi

\begin{tabular}{|l|l|}
\hline 6,037794811 & 11,78894779 \\
6,666731771 & 11,78894779 \\
6,666731771 & 16,13224434 \\
7,111180555 & 8,284125472 \\
7,272798295 & 11,78894779 \\
\hline
\end{tabular}

8. Menentukan matriks solusi ideal positif \& matriks solusi ideal negatif Langkah selanjutnya yaitu menentukan matriks solusi ideal positif dan matrik solusi ideal negatif :

Matriks solusi ideal positif (Yij+):

$$
\mathrm{A}^{+}=\left(\mathrm{Y}_{1}^{+}, \mathrm{Y}_{2}^{+}, . \mathrm{Y}_{3}^{+}, \ldots \ldots . \mathrm{Y}_{\mathrm{n}}^{+}\right) \text {; }
$$


$\mathrm{A}^{-}=\left(\mathrm{Y}_{1}^{-}, \mathrm{Y}_{2}^{-}, . \mathrm{Y}_{3}^{-}, \ldots . . . \mathrm{Y}_{\mathrm{n}}^{-}\right)$

$\left\{\begin{array}{l}\max (y i j) \\ \min _{i}(y i j)\end{array}\right.$

Solusi ideal positif dihitung sebagai berikut :

$\mathrm{Y}_{1}{ }^{+}=\max \{6,037794811,6,666731771, \quad 6,666731771, \quad 7,111180555$, $7,272798295\}=7,272798295$

$\mathrm{Y}_{2}{ }^{+}=\max \quad\{11,78894779, \quad 11,78894779, \quad 16,13224434, \quad 8,284125472$, $11,78894779\}=16,13224434$

$\mathrm{A}^{+}=(7,272798295,16,13224434)$;

$\mathrm{Y}_{1}{ }^{-}=\min \{6,037794811,6,666731771,6,666731771,7,111180555,7,272798295\}$

$=6,037794811$

$\mathrm{Y}_{2}^{-}=\min \{11,78894779,11,78894779,16,13224434,8,284125472,11,78894779\}$

$=8,284125472$

$\mathrm{A}^{-}=(6,037794811,8,284125472)$;

Jarak alternatif Ai dengan solusi ideal positif

$\mathrm{Di}^{+}=\sqrt{\sum_{j=i}^{n}\left(y i^{+}-y i j\right)^{2}}$

$\mathrm{D} 1=$

$\sqrt{(6,037794811-7,272798295)^{2}+(11,78894779-16,13224434)^{2}=20,09922843}$

$\mathrm{D} 2=$

$\sqrt{(6,666731771-7,272798295)^{2}+(11,78894779-16,13224434)^{2}=19,47029148}$

$\mathrm{D} 3=$

$\sqrt{(6,666731771-7,272798295)^{2}+(16,13224434-16,13224434)^{2}=0,606066525}$

D4=

$\sqrt{(7,111180555-7,272798295)^{2}+(8,284125472-16,13224434)^{2}=61,75458752}$

D5=

$\sqrt{(7,272798295-7,272798295)^{2}+(11,78894779-16,13224434)^{2}=18,86422495}$

Jarak alternatif Ai dengan solusi ideal negatif

$\mathrm{Di}^{-}=\sqrt{\sum_{j=i}^{n}(y i j j-y i j)^{2}}$ 
$\mathrm{D} 1=$

$\sqrt{(6,037794811-6,037794811)^{2}+(11,78894779-8,284125472)^{2}=12,28377946}$

$\mathrm{D} 2=$

$\sqrt{(6,666731771-6,037794811)^{2}+(11,78894779-8,284125472)^{2}=12,91271642}$

$\mathrm{D} 3=$

$\sqrt{(6,666731771-6,037794811)^{2}+(16,13224434-8,284125472)^{2}=62,22190674}$

D4=

$\sqrt{(7,111180555-6,037794811)^{2}+(8,284125472-8,284125472)^{2}=1,073385744}$

D5=

$\sqrt{(7,272798295-6,037794811)^{2}+(11,78894779-8,284125472)^{2}=13,51878295}$

9. Langkah terakhir dalam perhitungan TOPSIS adalah mencari nilai preferensi untuk setiap alternatif yaitu :

$\mathrm{Vi}=\frac{D i^{-}}{D i{ }^{\top}+D i^{+}}$

$\mathrm{V} 1=\frac{12,28377946}{12,28377946+20,09922843}=0,379327933$

$\mathrm{V} 2=\frac{12,91271642}{12,91271642+19,47029148}=0,398749754$

$\mathrm{V} 3=\frac{62,22190674}{62,22190674+0,606066525}=0,990353556$

$\mathrm{V} 4=\frac{1,073385744}{1,073385744+61,75458752}=0,017084519$

$\mathrm{V} 5=\frac{13,51878295}{13,51878295+18,86422495}=0,417465326$

\section{KESIMPULAN}

Dari hasil penelitian yang dilakukan ada beberapa kesimpulan yang didapat :

1. Dari hasil perhitungan diatas :

a) Jika pelatih ingin menggunakan 1 penyerang maka no 3 mempunyai nilai tinggi yaitu Karim Benzema;

b) Jika pelatih ingin menggunakan 2 penyerang maka no 3 yang mempunyai nilai tinggi yaitu Karim Benzema dengan 48 kali penampilan dan 19 gol menjadi pilihan utama kemudian no 5 yang mempunyai nilai tinggi kedua yaitu Kylian Mbappé dengan 44 kali penampilan dan 26 gol;

2. Berdasarkan kesimpulan no $1 \mathrm{a}$ dan no $1 \mathrm{~b}$ diatas, pelatih tidak bisa mengasumsikan bahwa jika si pemain sudah banyak tampil bagi klubnya atau sudah banyak mencetak gol bagi klubnya menjadi pilihan utama bagi pelatih. Karena apabila 
menggunakan sistem komputasi, semua hal tersebut harus diperhitungkan terlebih dahulu sesuai dengan kebutuhan.

3. Keluaran dari $k$-means bergantung pada titik pusat data awal yang ditentukan secara acak. Oleh karena itu, harus menjalankan $k$-means beberapa kali dengan titik pusat data awal yang berbeda-beda untuk menghasilkan titik pusat data akhir yang kita anggap paling cocok dengan kebutuhan kita.

\section{SARAN}

Saran-saran yang dapat disampaikan untuk pengembangan sistem sebagai berikut:

1. Pada sistem yang dibuat hanya terdapat 13 pemain dan 2 atribut, diharapkan dalam pengembangan lebih lanjut sistem ini dapat mencakup lebih banyak kriteria.

2. Diharapkan dalam pengembangan selanjutnya tidak hanya terbatas pada posisi peyerang, karena di sepakbola ada juga terdapat posisi penting lainnya.

3. Diharapkan dalam pengembangan selanjutnya juga dapat menggunakan metode lain baik di dalam metode data mining maupun sistem pendukung keputusan lainnya.

\section{DAFTAR PUSTAKA}

[1] Ditdit Nugeraha Utama. 2017. Sistem Penunjang Keputusan : Filosofi, Teori dan Implementasi. Yogyakarta : Garudhawaca.

[2] Kadarsah Suryadi. 2015. Sistem Pendukung Keputusan. Bandung : Rosda

[3] Kusrini. 2007. Konsep Dan Aplikasi Sistem Pendukung Keputusan. Yogyakarta : Andi, Amikom.

[4] Yulius Eka Agung Saputra. 2013. Belajar dan Analisis Tuntas Statistik Berbasis Komputer. Bekasi : Mitra Wacana Media.

[5] Suliyanto. 2012. Analisis Statistik Pendekatan Praktis Dengan Excel. Yogyakarta : Andi.

[6] Dr. Suyanto, S.T., M.Sc., 2017. Data Mining Untuk Klasifikasi Dan Klasterisasi Data. Bandung : Informatika.

[7] Kusrini, Emha Taufiq Luthfi. 2009. Algoritma Data Mining. Yogyakarta : Andi.

[8] Fajar Astuti Hermawati. 2013. Data Mining. Yogyakarta : Andi.

[9] Johan Oscar Ong. 2013. Implementasi Algoritma K-Means Clustering Untuk Menentukan Strategi Marketing President University. Jurnal Ilmiah Teknik Industri Vol 12 No 1 (Juni 2013)

[10] Marsono, Ahmad Fitri Boy, Wulan Dari. 2015. Sistem Pendukung Keputusan Pemilihan Menu Makanan pada Penderita Obesitas dengan menggunakan Metode Topsis. Jurnal Ilmiah Saintikom Vol 14 No 3 (September 2015). 